\title{
Knowledge regarding general use of pesticides and training need of pesticide dealers of North Gujarat
}

\author{
M.R. PRAJAPATI*, V.T. PATEL, J.K. PATEL, K.P. THAKAR AND S.P. PANDYA \\ Department of Extension Education, C.P. College of Agriculture, S.D. Agricultural University, \\ S.K. NAGAR (GUJARAT) INDIA
}

\begin{abstract}
This study was conducted in Banaskantha, Sabarkantha and Mehsana district of Gujarat state. Three talukas from each distinct were selected randomly. Fifty dealers from each district were selected from the list obtained from the quality control office. Thus, final sample consisted of 150 dealers. The data were collected by personal interview. Based on the findings of the study, majority of the pesticide dealers had middle aged, educated up to higher secondary level, belonged to general caste, engaged in single occupation, membership in one or more organisation, used pesticides company as a source of information and received training from company. Overall they possessed medium level of knowledge. The personal attributes like age, caste, experience in pesticides dealing, information sources used and training received by them had found associated with their knowledge level regarding general and specific areas of plant protection. Awareness of time methods quantity and number of spray, diseases, IPM and bio control were the major areas of training need reported by majority of the pesticide dealers.
\end{abstract}

KEY Words : Training, Knowledge, Dealers

View Point Article : Prajapati, M.R., Patel, V.T., Patel, J.K., Thakar, K.P. and Pandya, S.P. (2015). Knowledge regarding general use of pesticides and training need of pesticide dealers of North Gujarat. Internat. J. Home Sci. Extn. \& Comm. Manage., 2 (2): 7983.

Article History : Received : 08.03.2015; Revised : 15.05.2015; Accepted : 14.06.2015 